\title{
Rates of Induced Technology from Investments in Research and Development*
}

\author{
ALBERT N. LINK \\ Auburn University
}

\section{Introduction}

Research and development encompasses a myriad of activities. Generally, "research" is defined as the primary search for technical or scientific advancement, and "development" refers to the translation of these advancements into product or process innovations. Conceptually, "research" and "develop-

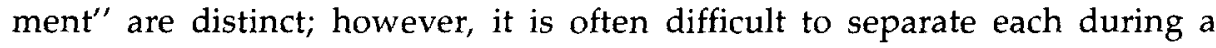
technical project or from resulting technology. Consequently, investments in the entire innovation process are commonly viewed under the heading of $R \& D$.

Since the pioneering study of "residual" growth by Solow [15], researchers have been concerned with measuring the impact of technological change on economic productivity. Assuming that one source of technology is induced research activity, investigators have asked: What is the nature of $R \& D$ in production and can its impact be measured?

It is extremely difficult to estimate the impact of $R \& D$ on production: simply, there is no unique measure of the output from $R \& D$. Some investigators $[8 ; 9 ; 12]$ assume that patents represent a reasonable index of induced technical knowledge; but, patented inventions vary markedly in quality and the number of patents may in fact not be related to the impact of any particular invention. "Moreover, since invention is one step removed from the application of new knowledge to production a relation between $R \& D$ and invention tells us nothing about the impact of $R \& D$ on the rate of measured technical progress" $[6,45]$.

Others view $R \& D$ investments as a proxy for technical capital and treat these expenditures as a direct input into the production process. This ap-

\footnotetext{
* The author wishes to thank E. C. H. Veendorp, Y. Horiba, and J. M. Trapani for comments on earlier versions of this paper.
} 
proach has been used by a number of writers $[2 ; 11 ; 16]$, particularly for industry studies in the manufacturing sector. The consensus is that the private rate of return to $R \& D$ is between 30 percent and 50 percent implying an under-investment in these activities. However, as Griliches notes, although these results are impressive they also are misleading and "too high by as much as 50 percent" $^{\prime \prime}[2,80]$. Their methodology implicitly ignores the transformation process between $R \& D$ as an investment and the resulting induced innovation by simply assuming proportionality between investments and technical output.

An alternative approach for assessing the impact of $R \& D$ on production is proffered in this paper. $R \& D$ investments are viewed as an instrument variable in the entrepreneur's profit maximizing decision process; and, in a Schumpeter-Usher $[14 ; 17]$ tradition, the role of $R \& D$ in production is modeled and measured. This model is formulated in Section II. In Section III a measure of the technical output from $R \& D$ is derived and evaluated using data from a sample of 2-, 3-, and 4-digit manufacturing industries. The impact of R\&D induced technology, measured from the model, on the growth of "residual" technology is then evaluated. Section IV concludes the paper.

\section{The Theoretical Model and Its Solution}

Assume a firm operates according to a linearly homogeneous production function written in terms of capital, $K$, and labor, $L:^{1}$

$$
Y=H\left(B_{1} K, B_{2} L\right) \text {. }
$$

$B_{1}$ and $B_{2}$ are factor augmenting coefficients assumed to result from R\&D investments. Notationally, let $m_{1}$ be the dollar amount of $R \& D$ devoted to $K$-augmentation, $B_{1}$; and let $m_{2}$ be the dollar amount of $\mathrm{R} \& \mathrm{D}$ devoted to $L$ augmentation, $B_{2}$ :

$$
\begin{aligned}
& B_{1}=B_{1}\left(m_{1}\right) \\
& B_{2}=B_{2}\left(m_{2}\right)
\end{aligned}
$$

where $B_{1}$ and $B_{2}$ are assumed to increase at a decreasing rate given increases in $m_{1}$ and $m_{2}$, respectively.

Associated with this production function is a linearly homogeneous cost function representing minimum factor usage:

$$
C\left(Y ; r / B_{1}, w / B_{2}\right)=Y G\left(r / B_{1}, w / B_{2}\right)
$$

for $r$ and $w$ constant unit factor costs of $K$ and $L$, respectively. ${ }^{2}$

1. The model presented here is patterned after a model suggested by Kamien and Schwartz

2. This result comes from Lemma I of Kamien and Schwartz [4, 669]. Proof rests on the duality theorem. 
Several characteristics of the firm's production process can be derived using equations (1) to (3): one, the shares of each factor in total cost are:

$$
\begin{aligned}
& r K / C=H_{1} B_{1} K / H=G_{1} r / G B_{1} \\
& w L / C=H_{2} B_{2} L / H=G_{2} w / G B_{2}
\end{aligned}
$$

where the subscripts on $H$ and $G$ denote partial derivatives with respect to the factor inputs. ${ }^{3}$ Two, the effect of factor augmentation is to reduce the cost of production at any given rate:

$$
\begin{aligned}
& \partial C / \partial B_{1}=Y \partial G / \partial B_{1}=Y\left(-G_{1} r / B_{1}^{2}\right)=-\left(r K / B_{1}\right)<0 \\
& \partial C / \partial B_{2}=Y \partial G / \partial B_{2}=Y\left(-G_{2} w / B_{2}^{2}\right)=-\left(w L / B_{2}\right)<0
\end{aligned}
$$

demonstrating that cost reduction is not independent of the means by which factor augmentation occurs. ${ }^{4}$ And three, given a specified value of $B_{1}$ and $B_{2}$, the maximum net revenue of the firm is defined as:

$$
N\left(B_{1}, B_{2}\right)=\max _{Y}\left[p(Y) Y-C\left(Y ; r / B_{1}, w / B_{2}\right)\right]
$$

or:

$$
N\left(B_{1}, B_{2}\right)=\left[p\left(Y^{*}\right) Y^{*}-C^{*}\left(B_{1}, B_{2}\right)\right],
$$

where $Y^{*}$ is the output level providing this maximum, where $C^{*}$ is the associated production cost, and $p\left(Y^{*}\right)$ is an inverse demand function assumed stable.

$N\left(B_{1}, B_{2}\right)$ can be viewed as a level of potential net revenue given uncertainty exists in the transformation between the $R \& D$ investment and the resulting factor augmentation. Realistically, this uncertainty can be related to the unknown success of any $R \& D$ project or to the time lag between the initial investment and its impact on production. Hence using the results from equations (5) the potential rate of change in net revenue is:

$$
\begin{aligned}
& \partial N\left(B_{1}, B_{2}\right) / \partial B_{1}=-\partial C / \partial B_{1}=r K / B_{1}>0 \\
& \partial N\left(B_{1}, B_{2}\right) / \partial B_{2}=-\partial C / \partial B_{2}=w L / B_{2}>0
\end{aligned}
$$

Given this uncertainty, the expected rate of change in net revenue is defined here as the potential rate, from equations (8), weighted by some finite probability of successfully completing a particular R\&D project. Assuming that this probability depends on the internalized technical capabilities of the firm gained from economies in R\&D activity $[3 ; 10]$, it is written as: ${ }^{5}$

$$
0 \leqslant P\left(m_{1}+m_{2}\right)=P(m) \leqslant 1
$$

3. This result comes from Lemma II of Kamien and Schwartz $[4,670]$.

4. This result is stated as Theorem I by Kamien and Schwartz [4, 672] yet the proof is obvious from our equations (3) and (4).

5 . We are assuming that this probability is a function of technical effort and efficiency which are proxied by $R \& D$ expenditures per period [3]. 
where,

$$
\begin{aligned}
& d P(m) / d m>0 \\
& d^{2} P(m) / d m^{2}<0 .
\end{aligned}
$$

The expected rate of change in net revenue is thus:

$$
P(m)\left[\partial N\left(B_{1}, B_{2}\right) / \partial B_{1}+\partial N\left(B_{1}, B_{2}\right) / \partial B_{2}\right] .
$$

The firm is also assumed to select levels of $R \& D$ so as to maximize the expected rate of increase in profits each time period defined as the expected rate of increase in net revenue less the $R \& D$ cost to achieve that increase. The objective function therefore becomes:

$$
\text { maximize }\left\{P(m)\left[\partial N\left(B_{1}, B_{2}\right) / \partial B_{1}+\partial N\left(B_{1}, B_{2}\right) / \partial B_{2}\right]-m\right\} \text {. }
$$

Using equations (8) the first order maximizing condition is:

$$
\begin{aligned}
& \left\{\left[r K / B_{1}+w L / B_{2}\right] d P(m) / d m\right\}+\left\{\left[d\left(r K / B_{1}\right) / d m+d\left(w L / B_{2}\right) / d m\right] P(m)\right\} \\
& \quad=1 .
\end{aligned}
$$

Assume, for simplicity of solution, that induced technology is neutral such that $B_{1}=B_{2}=B$. This implies from equations (5) and equations (8) that the share of capital and labor in total cost are equal. ${ }^{6}$ Under this assumption the optimal $\left(^{*}\right)$ degree of cost reducing factor augmentation induced by $R \& D$ investments can be determined from equation (13). Defining for notational convenience: ${ }^{7}$

$$
\begin{aligned}
& Z=-(r K+w L) \\
& S=Z P(m) \\
& W=Z d P(m) / d m,
\end{aligned}
$$

the optimal value, $B^{*}$, is:

$$
B^{*}=e^{-\int(W / S) d m}\left[k+\int(-S)^{-1} e^{\int(W / S) d m} d m\right]
$$

for $k$ a constant of integration. ${ }^{8,9}$

6. Kennedy [5] and Samuelson [13] reached a similar conclusion. Their models suggest that innovation decisions are determined by available technologies and by the share of each factor in total cost. Equal factor shares implies that induced technology will be neutral.

7. Alternatively, it could have been assumed that the entrepreneur induced specific factor bias based on some expectation of future factor prices. If, for example, $q$ represents an index of expected changes in the rental-wage ratio, $q=(\Delta r / \Delta w)^{e}$, then the entrepreneur's decision function constraining the maximization could be:

$$
U\left(B_{1}, B_{2} ; m_{1}, m_{2}, q\right)=0 .
$$

8. $B^{*}$ is characterized by two interesting, yet theoretically predictable, properties: one, any exogenous increase in factor costs reduces the influence of factor augmentation; and two, any exogenous increase in the probability of success will increase factor augmentation.

9. Substituting equations (14) into equation (13) and assuming neutrality, equation (13) takes the form of a Bernoulli equation. Equation (15) is then the solution of this equation for $B^{*}$. 
A solution to equation (15) will yield a measure of optimal factor augmentation induced through the firm's R\&D activity. Mathematically, the solution depends on the functional form of $P(m)$. As we have assumed, the probability of success of R\&D activity is an increasing function of the effort devoted toward that project. Mansfield [10] suggests such a probability function has the form:

$$
P(m)=1-e^{-\alpha m}
$$

where $\alpha$ is a firm specific constant and $m$ are the dollar $R \& D$ expenditures which approximate some degree of technical effort. ${ }^{10}$ Thus, equation (15) solves as:

$$
B^{*}=\left[k^{*}+m /(r K+w L)\right] /\left[1-e^{-\alpha m}\right]
$$

where $k^{*}$ is a new constant of integration viewed here as a firm specific index of technical or entrepreneurial ability. ${ }^{11}$

If a firm is in equilibrium and conforms to the assumptions of this model, the optimal rate of increasing net revenue through $R \& D$ activity depends on the resultant rate of factor augmentation. This rate of change in $B^{*}$ can be numerically approximated from equation (17) given values for $R \& D$ expenditures, total cost, and the constants $k^{*}$ and $\alpha$.

\section{The Empirical Analysis and Data Set}

The empirical analysis of this paper is concerned with first, assessing the impact of investments in $R \& D$ on production and second, measuring the extent to which induced $R \& D$ technology can account for growth in residually measured technology.

10. As assumed in equation (10):

$$
\begin{aligned}
& d P(m) / d m=\alpha e^{-\alpha m}>0 \\
& d^{2} P(m) / d m^{2}=e^{-\alpha m}\left(1-\alpha^{2}\right)<0
\end{aligned}
$$

for $\alpha>1$.

11. As required theoretically from equations (2), given our neutrality assumption, $d B^{*} / d m>0$ and $d^{2} B^{*} / d m^{2}<0$. If we write $B^{*}=g(m) / h(m)$ where $g(m)=\left[k^{*}+m /(r K+w L)\right]$ and $h(m)=$ $\left[1-e^{-\alpha m}\right]$, the first order condition implies that $[h(m)(d g(m) / d m)-g(m)(d h(m) / d m)]>0$. Mathematically, this condition is insured when:

$$
k^{*}<1 / J\left[e^{\alpha m} / \alpha-1 / \alpha-m\right]
$$

Recall that $\alpha$ and $k^{*}$ are firm specific technical indices. Given two firms with equal R\&D expend1tures, differences in the probability of success of each are reflected in $\alpha$. Given two firms with equal factor costs, $R \& D$ expenditures, and $\alpha^{\prime}$, differences in the optimal degree of induced factor augmentation are reflected in $k^{*}$. If we presume that $\alpha$ and $k^{*}$ reflect similar characteristics of the firm's R\&D efficiency or overall entrepreneurial ability; then, ceteris paribus, the above inequality is interpreted as defining this proportionality factor.

The second order condition, $d^{2} B^{*} / d m^{2}<0$, follows directly given that $d B^{*} / d m>0$. This can simply be demonstrated since $d^{2} g(m) / d m^{2}=0$ for $g(m)=\left[k^{*}+m /(r K+w L)\right]$. 
$B^{*}$ from equation (17) represents an index of the output from $R \& D$ generated within the production process. It should be noted that any numerical approximation of $B^{*}$ will suffer from several interpretative problems. First, what is the relevant measure of an R\&D expenditure? Published data sources are of course plagued with inconsistencies in accounting procedures regarding that actually included under the heading R\&D and that referred to as " $m$ " in our model. One could justly argue that $B^{*}$ should be a function of the stock of $R \& D$ knowledge rather than the flow of inputs into the creation of such knowledge. How then does such knowledge accumulate or depreciate? Second, what is the time lag between the $R \& D$ investment and its impact on production? It has been estimated that the lag on basic research is between five to eight years and on applied and development research between two to three years [2]. However, without knowledge of the rate of obsolescence associated with any particular project these measures are only approximate. Third, at what level of aggregation is $B^{*}$ empirically meaningful? Our model is formulated in terms of firm behavior; however, resulting productivity from $\mathrm{R} \& \mathrm{D}$ in one firm or industry may also depend on that resulting in other related firms or industries. The strength of these cross effects is unknown, a priori, but may be less important at a more aggregate level than the firm [2].

We are aware of the data problems regarding $R \& D$; however, we can offer no substantial alternative. Rather, an empirical approximation of equation (17) is made with the knowledge of these deficiencies. Estimates are made from data in the U.S. manufacturing sector-the largest single classification within the economy and the primary source for other R\&D assessment studies $[2 ; 7 ; 11 ; 16]$.

$B^{*}$ for 1963 was estimated using a cross-sectional sample of $452-$, 3-, and 4-digit manufacturing industries selected from a 1958 National Science Foundation survey of R\&D activity published in Industrial $R \mathcal{E} D$ Funds (NSF 64-25). The variables in equation (17) were measured as follows. The constant of integration, $k^{*}$, was assumed equal across industries and given an arbitrary value of 1 . R\&D investments, $m$, were measured as total $R \& D$ expenditures for each industry in 1958. Production costs, $(r K+w L)$, were measured as 1963 value added under the competitive assumption of product exhaustion. We are explicitly assuming a lag between the $R \& D$ investment and its impact on production. The five year period partly corresponds to the contentions of other researchers $[2,10]$ as well as to the paucity of available data. Value added is published in the Annual Survey and Census of Manufactures. The industry specific constant, $\alpha$, is not an observable datum and was therefore estimated for each industry. Mansfield [10] contends that a reasonable estimate for the probability of success in $R \& D$ activity for the coal and petroleum industries is 0.75 . Assuming that all industries in manufacturing enjoy this 
same probability of success for an average cross-industry level of $R \& D$ investments, $\overline{R D}_{58}, \alpha$ is determined for each industry from:

$$
.75=1-e^{-\alpha\left(\overline{R D}_{58}\right)} \text {. }
$$

Given published data on $R \& D$ investments only for 1958 , the annual percentage rate of increase in factor augmentation between 1958 and 1963 was estimated on the assumption that $B^{*}=1$ for 1958 . These figures are shown in Table I.

Table I. Average Annual Rates of Induced Factor Augmentation by Industry:

\begin{tabular}{ll}
\hline SIC Classification & Average Annual Rate \\
\hline $201,202,203$ & 0.0786 \\
204,205 & 0.0861 \\
206 & 0.0961 \\
207 & 0.0807 \\
21 & 0.0800 \\
226,228 & 0.0911 \\
$225,227,229$ & 0.0992 \\
232,2311 & 0.0867 \\
235,238 & 0.0741 \\
239 & 0.0900 \\
$241,242,243$ & 0.0826 \\
244,249 & 0.0813 \\
25 & 0.0879 \\
2711 & 0.0830 \\
2721 & 0.0928 \\
273 & 0.0997 \\
278,279 & 0.0800 \\
283 & 0.1036 \\
$284,2851,287$ & 0.0982 \\
30 & 0.0969 \\
31 & 0.0742 \\
3211,322 & 0.0901 \\
3241 & 0.0745 \\
325,327 & 0.0904 \\
329 & 0.0934 \\
3312 & 0.0840 \\
331 & 0.0888 \\
333 & 0.0985 \\
3411 & 0.0843 \\
342,343 & 0.0889 \\
344 & 0.0905 \\
3461,347 & 0.0933 \\
3481,349 & 0.0895 \\
351,3522 & 0.0906 \\
$353,354,355$ & 0.1013 \\
356 & 0.0960 \\
357 & 0.1464 \\
358,3599 & 0.0960 \\
36 & 0.1416 \\
371 & 0.1321 \\
373 & 0.0715 \\
3721 & 0.1476 \\
$3722,3723,3729$ & 0.1456 \\
3861,387 & 0.1208 \\
391 & \\
\hline &
\end{tabular}


There are several qualifications regarding the empirical accuracy of these rates aside from the obvious data problems associated with $R \& D$. First, these rates may be too low since $B^{*}$ was calculated assuming that induced technology was neutral and process augmenting rather than partly factor augmenting [2]. Second, $k^{*}$ in equation (17) was assumed equal across industries for empirical purposes although its economic interpretation was as a firm (or industry) specific index of technical or entrepreneurial ability. Not only does the arbitrary choice of $k^{*}=1$ impose an overall scale distortion to these calculated rates, but it creates a cross-industry bias. Presumably, $k^{*}$ is greater for those industries more intensely engaged in R\&D and innovation. Third, a similar cross-industry bias exists due to the assumption that $B^{*}=1$ for 1958 . Although data limitations necessitate such an assumption, the calculated rates are overstated for the more innovative firms in 1958 and understated for the least. The total impact of these shortcomings is not able to be determined. Nevertheless, using the annual rates from Table I, the overall industry average rate was 9.52 percent. Over this same time period, 1958-63, the industry average annual rate of increase in $R \& D$ investments was 8.06 percent implying over an 18.8 percent return to $R \& D$. This rate of return is considerably below the 30 to 50 percent range previously suggested; however, given the theoretical nature of our methodology vis-à-vis that of other researchers this figure is not unreasonable and may in fact be more accurate.

Customarily, technological change has been measured by a residually calculated index of those changes in output not attributable to changes in factor inputs. Boddy and Gort [1] have recently shown that one source of technology captured by such an index is capital embodiment. Griliches [2] has identified induced technologies as an additional source of technical growth by regressing $R \& D$ intensity on a residual technology index. Perhaps a more meaningful test of the relationship between the residual, $T$, and induced sources of technology can be formulated using an explicit measure of induced technology, $B^{*}$, rather than simply $\mathrm{R} \& \mathrm{D}$ expenditures.

Assume a linear reduced-form equation as the basis for this estimation:

$$
\dot{T} / T=\beta_{0}+\beta_{1}\left(B^{*} / B^{*}\right)+\beta_{2} D+\mu .
$$

$\hat{\beta}_{1}$ will indicate the significance of inducement as a source of technology empirically captured by the residual. $D$ is a dummy variable to be discussed below and $\mu$ is a random error term for estimation purposes.

For each industry in the sample the percentage change in the residual is calculated as:

$$
\begin{aligned}
\dot{T} / T= & 1 / 5\left[\left(\ln Y_{63}-\ln Y_{58}-\ln P D\right)-A S L\left(\ln L_{63}-\ln L_{58}\right)\right. \\
& \left.-(1-A S L)\left(\ln K_{63}-\ln K_{58}\right)\right]
\end{aligned}
$$

where $Y$ represents value added, $P D$ is an industry specific price deflator $(1958=100)$ for value added, $L$ is measured as total employment, $K$ is mea- 
sured as the gross book value of fixed assets, and ASL is the average share of labor in value added. Value added, total employment, and gross book value of fixed assets were taken from the Annual Survey and Census of Manufactures and the price deflator was taken from the 1963 Census of Manufactures Indices of Production (Vol. 4, Table 5) [2].

In two industries, Ordnance and Aircraft and parts (SIC 19 and 372), about 86 percent of total $R \& D$ investment is government financed. A dummy variable, $D$ equaling 1 , is included for these industries since their contributions of $R \& D$ to production is not likely to be captured in the measured residual [2].

The estimated regression line is:

$$
\begin{aligned}
& T / T=-0.06+0.71\left(\dot{B}^{*} / B^{*}\right)-0.24 D \\
& (-2.52) \quad(2.79) \quad(-1.05) \\
& \text { F-level }=4.15 \quad R^{2}=0.165 \quad n=45
\end{aligned}
$$

Over 16 percent of the industry variation in the residual is explained by variation in the rate of growth of induced technology. $\hat{\beta}_{1}$ is highly significant verifying the empirical reliability of our theoretical model across-industry. The coefficient on $D$ is negative, as others have found $[2,16]$, but not significant. ${ }^{12}$

\section{Conclusion}

What then is the role and impact of $R \& D$ on a firm's production process? In this paper a framework for modeling the transformation between a firm's investments in $R \& D$ and the resulting technological output has been suggested. Although the model is simplistic in its assumptions of neutrality and myopic optimization and as well the available figures on $R \& D$ expenditures are wanting, reasonable and perhaps more accurate estimates of the role and impact of $R \& D$ in production are presented.

12. The rates of induced technology reported in Table I overexhaust the residual in all of the 45 industries. However, an industry by industry numerical comparison of each series is unjustified in terms of the potential scale distortions in the rates calculated from equation (17). We can only assume in estimating equation (19) that the estimating bias is primarily an overall scale factor rather than a cross-industry phenomenon. 


\section{References}

1. Boddy, M. and L. Gort, "Obsolescence, Embodiment, and the Explanation of Productivity Change." Southern Economic Journal, April 1973, 553-62.

2. Griliches, Z., "Research Expenditures and Growth Accounting," in Science and Technology in Economic Growth, edited by R. B. Williams. New York: John Wiley \& Sons, 1973.

3. Kamien, M. I. and N. L. Schwartz, "Expenditure Patterns for Risky R and D Projects." Journal of Applied Probability, March 1971, 60-73.

4. point." Econometrica, October 1969, 668-84.

5. Kennedy, C., "Induced Bias in Innovation and the Theory of Distribution." The Economic Joumal, September 1964, 541-47.

6. $1972,11-72$

7. Leonard, W. N., "Research and Development in Industrial Growth." Journal of Political Economy, March/April 1971, 232-56.

8. Mansfield, E., "Industrial Research and Development Expenditures: Determinants, Prospects, and Relation to Size of Firm and Inventive Output." Journal of Political Economy, August $1964,319-40$.

9. "Industrial Research and Development: Characteristics, Costs and Diffusion of Results." American Economic Review, May 1969, 65-71.

10. Industrial Research and Technological Innovation. New York: W. W. Norton \& Company, Inc., 1968.

11. _. "Rates of Return from Industrial Research and Development." American Economic Review, May 1965, 310-22.

12. Mueller, D. C., "Patents, Research and Development, and the Measurement of Inventive Activity." Journal of Industrial Economics, November 1966, 26-37.

13. Samuelson, P. A., "A Theory of Induced Innovation Along Kennedy-Weisacker Lines." The Review of Economics and Statistics, November 1965, 343-56.

14. Schumpeter, J. A. The Theory of Economic Development. Cambridge: Harvard University Press, 1934.

15. Solow, R. M., "Technical Change and the Aggregate Production Function." The Review of Economics and Statistics, February 1957, 312-20.

16. Terleckyj, N. W. Effects of $R \mathcal{E} D$ on the Productivity Growth of Industries: An Exploratory Study. Washington: National Planning Association, 1974. 1954.

17. Usher, A. P. A History of Mechanical Inventions. Cambridge: Harvard University Press, 
Copyright of Southern Economic Journal is the property of Southern Economic Association and its content may not be copied or emailed to multiple sites or posted to a listserv without the copyright holder's express written permission. However, users may print, download, or email articles for individual use. 